\title{
VOLTANDO AOS EXAMES DE ADMISSÃO AO GINÁSIO (1930-1970): A RELAÇÃO ENTRE A MATEMÁTICA DOS EXAMES COM A MATEMÁTICA A ENSINAR E ENSINADA NAS ESCOLAS
}

\section{Going back to the admission exams to the gymnasium (1930-1970): the relationship between mathematics of exams with mathematics to teach and taught in schools}

Késia Caroline Ramires Neves - Universidade Federal de Mato Grosso do Sul/Brasil Fernanda Cristina Martins Martti - Universidade Federal de Mato Grosso do Sul/Brasil Dina Elizabete Alfonso - Universidade Federal de Mato Grosso do Sul/Brasil

RESUMO: O presente artigo trata de resultados de uma metanálise realizada sobre trabalhos acadêmicos de perspectiva histórico-investigativa, os quais discutiram acerca da implantação e desenvolvimento dos exames de admissão ao ginásio realizados no Brasil entre 1930 a 1970. Focaliza o papel desses exames no contexto educacional da época e, principalmente, busca evidenciar a relação da matemática que era exigida nos testes com a matemática que era programada e ensinada nas escolas, ou seja, discute a possível relação entre a matemática dos exames e a matemática a ensinar e ensinada. A metanálise se concentrou em 3 dissertações que foram encontradas no banco de dados da Biblioteca Digital de Teses e Dissertações. Realizada essa etapa, um dos resultados obtidos foi de que não havia dissonância quanto à matemática a ensinar no primário e aquela que era exigida nas provas. Dessa forma, foi possível constatar a não imposição dessa política avaliativa para que mudanças ocorressem ao programa de ensino da matemática do primário. Porém, os exames surtiram outros efeitos importantes sobre a escola, tais como: fora aumentado em um ano a fase dos primeiros anos escolares, sendo o quinto e último destinado à preparação dos alunos para os testes; outro indício encontrado foi de que os exames teriam influenciado a prática de ensino da matemática dos professores do primário. Assim, há elementos para o aprofundamento de novas pesquisas direcionadas ao debate acerca dos efeitos dos exames nacionais junto ao trabalho do professor.

Palavras-chave: Exame de admissão ao ginásio. Matemática. Prática docente.

ABSTRACT: This article talk about the results of a meta-analysis on academics works from historical-investigative perspective, wich discussed about the implementation and development of admission exams to the gymnasium in Brazil between 1930 and 1970. Focuses on the role of these exams in the educational context of the time and, mainly, it seeks to highlight the relationship of mathematics of exams that was required in tests to mathematics that was programmed and taught at schools, in other words, discusses the possible relationship between the exams mathematics and the mathematics to teach and taught. The meta-analysis focused on 3 dissertations which were found in the database of the Digital Library of Theses and Dissertations. Performed this step, one of the results obtained was that there was no dissonance about mathematics to teach in primary and the one that was required in the tests. Thus, it was possible to verify the nonimposition of this evaluative politics for changes to occur to the mathematics teaching program of the primary school. However, exams had other importante effects on school, such as: the phase of the first school years had been increased by one year, other evidence

Educação, Psicologia e Interfaces, Volume 3, Número 3, p. 64-78, Setembro/Dezembro, 2019.

ISSN: 2594-5343. DOI: https://doi.org/10.37444/issn-2594-5343.v3i3.206 
found was that the exams would have influenced the mathematics' teaching practice of primary school teachers. Therefore, there are elements for future research directed to the debate about the effects of national examinations on the teacher's work.

Keywords: Entrance exam to the Gymnasium. Mathematics. Teaching practice.

\section{INTRODUÇÃO}

O presente trabalho é resultado de uma pesquisa que está vinculada ao Grupo de Estudos e Pesquisa em Educação Matemática Escolar - GEPEME - e faz parte de um projeto cadastrado na Universidade Federal de Mato Grosso do Sul, intitulado “A História da Matemática Escolar: contribuições para o campo de pesquisa e formação de professores". Como Grupo interessado na história da matemática escolar, procuramos desvelar minúcias do passado para compreender as consequências que constituem o presente e também propor ações e/ou resultados a fim de contribuir com a formação docente. Em específico, neste trabalho, buscamos na história dos exames de admissão ao ginásio (décadas de 1930 a 1970), informações sobre a relação da matemática exigida nos exames com a matemática programada às escolas, ou seja, quais seriam as possíveis intervenções de uma matemática dos exames sobre uma matemática a ensinar no primário, ou vice-versa.

Um dos significados para o termo matemática a ensinar tem sido cunhado pelo pesquisador Wagner Rodrigues Valente e sua equipe do Grupo de Pesquisa de História da Educação Matemática no Brasil - GHEMAT/Brasil. Em produções recentes, o grupo explica que a matemática a ensinar se refere aos saberes "estritamente matemáticos, disciplinares" (BERTINI; MORAIS; VALENTE, 2017, p. 59), emanados dos campos de referência, pelas disciplinas universitárias (LUSSI BORER, 2009). Trata-se de saberes já sistematizados e constituintes da formação docente do professor que ensina matemática (VALENTE, 2018). Por conseguinte, esta matemática a ensinar seria aquela prescrita em documentos oficiais, objeto de ensino dos professores, o que ensinar, ou seja, a matemática a ser ensinada nas escolas, uma matemática do e para o currículo escolar, revelada tanto na formação de professores, como também mobilizada no ensino.

O termo, ainda, resulta em uma matemática que conjuga saberes estritamente matemáticos, oriundos do campo matemático, junto a uma dada pedagogia da época. Por 
exemplo: da sistematização da matemática acadêmica com a pedagogia intuitiva, originase uma matemática a ensinar que traz marcas da marcha intuitiva.

Ainda que o termo seja novo e categoria teórica a ser explorada, este artigo traz a matemática a ensinar com outra conotação, aquela estritamente acadêmica, sem veios de vagas pedagógicas. A opção por essa conotação basea-se na premissa de que os exames perpassaram vagas pedagógicas distintas e, portanto, não estamos discutindo a matemática dos exames com as matemáticas produzidas por pedagogias distintas, mas sim buscando as relações entre a matemática dos exames com aquele rol de assuntos estritamente matemáticos que constavam em programas de ensino oficiais e que, possivelmente, foram ensinados.

Quanto à matemática dos exames, propomos o termo fazendo alusão àquela matemática prescrita em documentos oficiais de admissão ao ginásio, ou seja, a matemática que deveria ser exigida nas provas $^{1}$ dos exames. Assim, ainda que tenhamos filiação com o grupo GHEMAT/Brasil, não estamos mobilizando o termo matemática a ensinar com o mesmo significado que nossos colegas, pois estamos tratando apenas de compreender a relação sobre "matemáticas" prescritas em documentos oficiais que serviram de orientação para os conteúdos a ensinar e avaliar.

Nossa hipótese inicial é a de que o programa prescrito da matemática dos exames não contemplaria todos os conteúdos prescritos ao primário, e que, por esse motivo, os exames poderiam ter direcionado o ensino do primário, limitando os conteúdos a serem ensinados, circunscrevendo-os somente àqueles para preparação aos testes/provas dos exames. Consequência disso, ter-se-ia um ensino primário sujeito aos processos de admissão ao ginásio. Veremos o que a pesquisa nos mostrou!

Assim, a metanálise sobre trabalhos que usaram da perspectiva históricoinvestigativa se mostrou de extrema importância para levantar elementos que poderão sucitar futuras pesquisas.

\section{MATERIAL E MÉTODO}

Neste trabalho, optamos por realizar, primeiramente, uma metanálise ${ }^{2}$ sobre resultados acadêmicos, uma vez que a nossa pesquisa ainda se encontra em fase inicial e necessitamos de um olhar crítico sobre a nossa própria hipótese. Então, para essa fase inicial, partimos de uma metanálise realizada sobre três dissertações que trataram dos

Educação, Psicologia e Interfaces, Volume 3, Número 3, p. 64-78, Setembro/Dezembro, 2019. 
exames de admissão ao ginásio, realizados em São Paulo e Paraná, entre 1930 a 1970.os trabalhos também investigaram sobre a matemática das provas e aquela programada ao ensino. Focalizando o papel desses exames no contexto educacional da época, procuramos nessas produções uma comparação entre o programa de matemática exigido nesses exames com aquele que era programado às escolas para então discutir uma possível dependência ou independência do ensino primário em relação à política dos exames. Para além disso, também averiguamos se houve algum efeito da política avaliativa sobre o ensino que fora ministrado por professores de matemática do primário.

Para subsidiar a pesquisa, realizamos uma seleção bibliográfica a partir de teses e dissertações cadastradas na Biblioteca Digital Brasileira de Teses e Dissertações (BDTD), uma vez que essa biblioteca, atualmente, parece estar mais completa que as demais (das que são digitais). O recorte para seleção dos trabalhos foi baseado em palavras-chave divididas em três agrupamentos, sendo o primeiro com o uso dos descritores "exame de admissão", "ensino secundário" e "matemática". Para esse caso, em que tivemos 3 descritores cruzados de 6 formas distintas, obtivemos apenas 3 dissertações, sendo que 1 delas atendia a nossa pesquisa, a dissertação de Rita de Cassia Gomes Machado (de 2002): Uma análise dos exames de admissão ao secundário (1930-1970): subsídios para a história da educação matemática no Brasil. Uma segunda seleção foi realizada pelo baixo número de trabalhos encontrados na primeira tentativa. Assim, para o segundo caso, efetuando a busca pelo descritor "exame de admissão", encontramos 24 trabalhos, com 3 deles sendo repetidos duas vezes na lista apresentada pela Biblioteca. Logo, foram encontrados 21 trabalhos diferentes. Desses, 3 foram pertinentes ao nosso estudo, o trabalho de Rosemary Santos (de 2017): Saberes matemáticos identificados em provas do exame de admissão ao ginásio do colégio São Paulo (1931-1969), o de Elizângela Zarpelon Aksenen (de 2013): Os exames de admissão ao ginásio, seu significado e função na educação paranaense: análise dos conteúdos matemáticos (1930-1971) e o de Rita de Cassia Gomes Machado, já citado na primeira busca. Na terceira tentativa de rastreamento, usamos o descritor de busca "admissão ao ginásio" e obtivemos o mesmo trabalho de Rosemary Santos. Por isso a nossa metanálise se concentrou em apenas 3 dissertações.

Para nortear essa metanálise, partimos de cinco questões preliminares: O que foi o exame de admissão ao ginásio? Qual sua finalidade? Quais conteúdos matemáticos eram exigidos nas provas dos exames? Como esses conteúdos eram abordados nas 
questões das provas? Houve alguma interferência da "matemática dos exames" sobre a "matemática a ensinar" nas escolas (especificamente no primário³)? Com os resultados desses trabalhos, as quatro primeiras questões foram respondidas rapidamente e puderam adiantar caminhos a seguir na investigação. Restou apurar a última delas, ainda não discutida nos materiais encontrados, e também tema central deste artigo: saber se houve alguma interferência/relação da matemática dos exames sobre a matemática a ensinar nas escolas.

Como questão principal, procuramos responder: a matemática que era exigida nos exames "moldou" o que seria destaque no ensino da matemática escolar? Ou melhor: a matemática dos exames interferiu no que se deveria ensinar ou no que foi ensinado no primário? Vale lembrar que a investigação se limitou a olhar para os exames aplicados em São Paulo e Paraná, pois foram os estados dos trabalhos encontrados na BDTD.

As três dissertações nos forneceram informações específicas sobre os exames de admissão ao ginásio (as finalidades, o período em que esses permaneceram no processo educacional brasileiro, entre outras informações), bem como sobre os conteúdos matemáticos exigidos nas provas e sobre a forma didática e os tipos de questões que apareciam. Além disso, como se basearam em documentos oficiais (como regulamentos, leis, programas de ensino, decretos, portarias) e provas, os 3 trabalhos também puderam nos informar sobre a normatização dos exames e as relações e/ou consequências que essa política imprimiu naquela época. Quanto à relação da matemática dos exames com a matemática a ensinar e a que foi ensinada, alguns resultados nos trouxeram novas pistas para futuras pesquisas.

A seguir, vamos apresentar brevemente como foi a passagem dos exames de admissão ao ginásio até os anos 1970, como essa política avaliativa foi criada, qual era seu real objetivo, o período em que o exame passou a ser obrigatório nacionalmente, como eram constituídas as provas (conteúdos que eram cobrados nos exames) e se houve alguma relação de dependência da matemática a ensinar ou ensinada no primário com a dos exames.

\section{O CONTEXTO DOS EXAMES DE ADMISSÃO AO GINÁSIO}

De acordo com Machado (2002), o ensino no Império (1822-1889) dispunha de um caráter propedêutico, em que o objetivo era preparar o aluno para o ensino superior.

Educação, Psicologia e Interfaces, Volume 3, Número 3, p. 64-78, Setembro/Dezembro, 2019. 
Voltando aos exames de admissão ao ginásio (1930-1970): a relação entre a matemática dos exames com a matemática a ensinar e ensinada nas escolas

Havia, na época, dois mecanismos de ensino, um que era responsável pelo ensino primário e secundário, que era o provincial (de responsabilidade das Províncias), e outro que era responsável pelo ensino superior, o geral (de responsabilidade do Governo Central). O ensino secundário era influenciado pelo poder geral, já que era um dos meios de ingressar no ensino superior. Já o ensino primário sofria um descaso da sociedade, pois ele era destinado aos filhos das classes populares e não era obrigatório cursá-lo para ingressar no próximo nível de ensino, "o aluno poderia simplesmente solicitar a realização do exame de uma disciplina em determinado estabelecimento de ensino secundário, sem ser precedido de sua participação às aulas" (DALLABRIDA, 2009, p. 187).

Os primeiros liceus foram criados no Brasil no século XIX e foram mantidos com muitas dificuldades. Não possuíam um conjunto organizado de aulas, eram aulas avulsas sem uma sequência de disciplinas, em que os alunos "escolhiam a ordem e a quantidade de disciplinas que desejavam cursar" (MENEGHETI, 2012, p. 2). Segundo Menegheti (2012), o ensino secundário era destinado a uma minoria e a finalidade de sua criação era a de formar filhos da elite brasileira para ingressarem no ensino superior e, assim, ocuparem cargos de destaque na sociedade.

Mas após a Revolução de 1930, do governo de Getúlio Vargas, ocorreram várias mudanças que transformaram o cenário da educação brasileira. Foi criado o Conselho Nacional de Educação, aumentaram-se as redes de ensino primária e secundária e foram instituídas significativas reformas que objetivavam adequar o ensino à modernização do país (AKSENEN, 2013). Também foi criado o Ministério da Educação e da Saúde Pública, no qual Francisco Campos foi o primeiro titular.

O governo de Vargas deu enfoque ao desenvolvimento industrial e urbano e, com a expansão das indústrias, surgiu a necessidade de mão de obra especializada. Então, em 1931, Campos implementou uma reforma da educação brasileira que ficou conhecida como Reforma Francisco Campos, a qual tinha o propósito de modernizar o ensino secundário (DALLABRIDA, 2009). Trabalhando para isso, ou seja, para que emergisse uma classe de sujeitos aptos ao trabalho, Campos considerava o ensino secundário o mais importante nível de ensino. Ele propôs um curso prático que contribuísse na formação do homem para todos os setores da atividade nacional, compreendendo, ainda, o papel da escola como espaço a se trabalhar com as transformações da vida contemporânea, com a rapidez das comunicações, complexidade dos processos industriais, entre outros (AKSENEN, 2013, p. 19). A reforma proposta por Campos foi então homologada em um 
contexto de importantes mudanças no país, devido, sobretudo, ao desenvolvimento urbano e industrial.

Nessa reforma, com o Decreto $\mathrm{N}^{\circ} 19.890$ de 18 de abril de 1931, foram fixadas uma série de medidas, como o aumento da duração do curso secundário, passando de 5 para 7 anos, e sua divisão em dois ciclos. Além disso, determinava que a frequência às aulas seria obrigatória; que haveria a seriação do currículo (que, segundo Dallabrida, definia uma progressão obrigatória dos saberes escolarizados, permitia um maior controle sobre o processo de seleção, avaliação e organização) e que fosse imposto um sistema de avaliação discente e a reestruturação do sistema de inspeção federal.

No referido Decreto, Capítulo II, Art. 18, o exame de admissão fora fixado como exame nacional e obrigatório ${ }^{4}$, a fim de homogeneizar o ensino secundário em instituições públicas e privadas. As provas dos exames eram dissertativas e orais, na qual eram cobrados assuntos da disciplina Português (redação e ditado), Aritmética (cálculo elementar), Geografia, História do Brasil e Ciências Naturais e era aplicado aos alunos que terminassem a $4^{\mathrm{a}}$ série do ensino primário para tentarem o ingresso no ensino secundário. Como exame eletivo, o principal objetivo era controlar as matrículas dos alunos no ensino secundário, visto que não se tinha, naquela época, uma estrutura escolar que atendesse a todos os alunos concluintes do ensino primário. $\mathrm{O}$ candidato que passasse no exame de admissão, em seu primeiro ano do ensino secundário iria revisar os conteúdos do exame como uma espécie de continuação do primário, onde seriam reforçados e aprimorados alguns conceitos (MACHADO, 2002).

Essa política avaliativa perdurou por 40 anos, de 1931 a 1971, respaldada pela Lei 19.890/1931 até a Lei 5692/1971, quando o exame foi extinto. Mas como revela Machado (2002), mesmo após os exames não serem mais obrigatórios em território nacional, algumas escolas continuaram a usá-los como forma de seleção de seus alunos. Nesses 40 anos de existência, conforme Machado (2002), Aksenen (2013) e Santos (2017), "a quantidade de questões presentes em cada exame; as disciplinas exigidas nas provas; o cálculo da média final do aluno, como também a quantidade de professores envolvidos na correção", foram alterando-se. Mas, sobre os conteúdos, exposição didática das questões de matemática, ou nível de exigência/dificuldade das questões, poucas modificações ocorreram.

Educação, Psicologia e Interfaces, Volume 3, Número 3, p. 64-78, Setembro/Dezembro, 2019. 
Voltando aos exames de admissão ao ginásio (1930-1970): a relação entre a matemática dos exames com a matemática a ensinar e ensinada nas escolas

Na subseção a seguir, apresentamos a metanálise das três dissertações. Veremos como as pesquisas corroboraram para a compreensão da relação existente entre a matemática dos exames com a matemática a ensinar e ensinada no primário.

\section{RESULTADOS E DISCUSSÃO}

Nossa pesquisa, como já ressaltado na introdução, procurou responder cinco questões. Porém, por limites textuais, vamos nos concentrar na pergunta central: houve alguma interferência da matemática dos exames sobre a matemática a ensinar nas escolas? Tentando responder a essa indagação, vamos discutir as três dissertações entrelaçando informações. Cada trabalho selecionado será tratado pelo seu autor: Machado (2002), Aksenen (2013) e Santos (2017).

As dissertações de Machado (2002) e de Aksenen (2013) procuraram mostrar que os exames de admissão ao ginásio constituíram um marco importante para a história da educação brasileira, pois ninguém ascenderia ao secundário sem antes passar por essa política avaliativa. Quando esse exame tornou-se obrigatório também estabeleceu o primeiro passo para a seletividade daqueles que chegariam ao ensino superior. Além disso, com as provas de matemática, a seletividade foi demarcada ainda mais, pois os "famosos carroções" exigiam experiência e atenção redobrada dos alunos.

Machado analisou provas encontradas na antiga Escola Estadual de São Paulo (antigo Ginásio da Capital), provas do Colégio Pedro II, dentre outros documentos como decretos oficiais, programas de ensino e programas de exames de admissão. Um detalhe significativo constatado por ela nesses documentos foi o descrito na LDBEN, de 1965: o “exame de admissão tem por objetivo verificar se o candidato possui satisfatória instrução primária para ingressar na primeira série ginasial" e "poderá ser feito mediante a prestação de provas ou limitar-se-á verificação da autenticidade e idoneidade do certificado de aprovação em curso primário reconhecido e fiscalizado pela LDBEN $\mathrm{N}^{0} 4.024 / 61$ " (BRASIL, LDBEN, 1965).

Isso induz, a princípio, a pensarmos em um ensino primário com o mesmo rigor empregado na averiguação dos exames, pois se alunos que finalizassem o primário poderiam obter uma mesma certificação do que aqueles que prestassem o exame e fossem aprovados, então esperava-se o mesmo critério em ambas as situações. Porém, essa é apenas uma hipótese tendo em vista que nenhum dos trabalhos analisados discutiram as relações de interdependência (ou não dependência) entre o ensino do primário e os 
exames de admissão - o que nos traz uma pista para futuros estudos. O que de fato podemos afirmar é que mesmo sendo cobrada predominantemente a aritmética, nas provas de matemática dos exames, o ensino que se obtinha no primário não era uma garantia de que os alunos seriam aprovados para ingresso no secundário. Dessa forma, surgiram os cursos preparatórios de admissão a fim de compensar possíveis lacunas que pudessem ter ficado do primário.

Como evidenciado por Machado (2002), desde 1940 havia cursos preparatórios para aqueles que pudessem e quisessem pagar para se preparar para os exames de admissão. Entre as décadas de 1950 a 1960, após os 4 anos do primário, alunos que comprovassem baixa renda também poderiam cursar o preparatório, que era realizado por alguns meses (ou o ano inteiro, a depender da escola e espaço físico) até a data do exame. Assim, quem não pudesse pagar cursos particulares teria ao menos as mesmas condições de preparação. Ao que tudo indica, a matemática dos exames era tratada nesses cursos preparatórios, e não em momento à parte durante os 4 anos do primário (assim como acontece atualmente em que se destina um tempo do ensino fundamental, e médio, para preparar os alunos para as provas dos exames nacionais), ou seja, a matemática dos exames parece não ter influenciado a programação da matemática a ensinar no primário. Contudo, como consta em um depoimento coletado por Aksenen (2013), talvez um período do ano - de julho até dezembro - alguns professores já começassem a preparação dos alunos primários para o exame de admissão:

Vinha da Secretaria para a professora tudo o que a gente tinha que ensinar [...] a gente dividia o que trabalharia em cada mês. Quando chegava julho fazíamos somente recordação para poder fazer o exame no final do ano. Mas, primeiro tinha sabatina. Todo mês fazíamos uma sabatina. E no fim do ano era o exame, aí vinha tudo. Então a gente tinha isso, seguíamos aquilo que vinha da Secretaria (AKSENEN, 2013, p. 109 - depoimento oral de Z. B. B.).

Outros elementos, referentes à atuação dos professores em cursos de preparação aos exames, também colocam a relação entre a matemática a ensinar, e a matemática dos exames, em evidência. Por exemplo, pelo Decreto N. 27.017, de 14 de Dezembro de 1956,

Art. 10 - As aulas dos cursos referidos neste Decreto serão ministradas por professores estranhos ao quadro do respectivo estabelecimento, admitidos como extra-numerários mensalistas [...]. [...] Art. 12 - Os professores admitidos para a regência dos cursos deverão ser portadores, no mínimo, de diploma de normalista.

Educação, Psicologia e Interfaces, Volume 3, Número 3, p. 64-78, Setembro/Dezembro, 2019.

ISSN: 2594-5343. DOI: https://doi.org/10.37444/issn-2594-5343.v3i3.206 
Voltando aos exames de admissão ao ginásio (1930-1970): a relação entre a matemática dos exames com a matemática a ensinar e ensinada nas escolas

Art. 13 - Os professores admitidos, se forem ocupantes de cargo ou função docente, poderão assumir o exercício de suas novas funções ouvida, "a posteriori", a Comissão Permanente de Acumulações. Parágrafo único - $\mathrm{Na}$ admissão dos docentes dar-se-á preferência aos que não exerçam quaisquer outros cargos ou funções públicas ainda que legal a acumulação nos termos do Decreto 25.031 - A, de 15-10-1955 e alterações posteriores.

Art. 14 - A Secretaria da Educação fica obrigada a manter, durante a realização dos Cursos Intensivos de Preparatórios, rigorosa fiscalização a fim de através de critério objetivo apreciar periodicamente a eficiência dos cursos, o aproveitamento dos alunos e a tarefa dos Professores e de modo a assegurar aos escolares e seus responsáveis claro conhecimento sobre os possíveis sucessos ou insucessos nos exames de admissão (BRASIL, 1956).

Vemos que professores, no mínimo normalistas, foram chamados a lecionar nos cursos preparatórios, alguns possivelmente acumulando encargos docentes entre o ensino no primário e em cursos de preparação aos exames. Como nos parece que o nível de exigência e fiscalização das aulas desses cursos preparatórios eram mantidos à risca, os professores que atuavam nesses cursos e em outras escolas podiam acumular também práticas de ensino, modificando, inclusive, aquelas já estabelecidas. Dessa forma, não podemos nem generalizar e nem afirmar que professores primários (ou do secundário) tenham mudado sua prática a partir do trabalho com os exames de admissão, mas alguns indícios nos mostram que isso não foi longe do esperado, ou seja, professores podem ter mobilizado a matemática a ensinar na escola de maneira acordada à matemática dos exames.

Em outro depoimento colhido por Aksenen (2013), um professor relata que tornou-se professor suplementar do ginásio, preparando as provas do exame de admissão da instituição onde trabalhava: "As provas não vinham do Estado, deveriam ser preparadas pela própria instituição. Então, os professores as elaboravam e também aplicavam, sem pagamento adicional para tal" (AKSENEN, 2013, p. 101 - depoimento oral de T. D. F.). Outro depoimento coletado pela mesma pesquisadora revela que uma professora normalista que foi atuar junto aos cursos de preparação aos exames, teve resultados a partir de sua nova experiência (referindo-se à experiência de preparar alunos para os exames):

Esse trabalho veio contribuir com a minha experiência, uma vez que a partir de $1^{\circ}$ de março de 1968 até 31 de janeiro de 1969, estava contratada para exercer o cargo de Orientadora Educacional no Serviço de Educação Municipal", [...]. Obs.: O cargo de Orientadora Educacional, nessa época, realizava o mesmo trabalho que a Supervisão 
faz hoje. Preparava material para professores municipais que trabalhavam na zona rural, sobre os conteúdos do bimestre, elaborava as provas bimestrais e também os exames finais. (AKSENEN, 2013, p. 102,103 - depoimento oral de I. B. V.)

Portanto, as relações imbricadas entre ensinar para o primário (ou secundário) e preparar alunos ou provas para os exames de admissão, não eram relações superficiais. Muito pelo contrário, elas poderiam ser factíveis e poderiam levar professores a mudar suas práticas de ensino. Logo, esse é um indício que tem muito para ser explorado em continuidade desta pesquisa.

Alguns anos mais tarde, a Circular $\mathrm{N}^{\circ}$ 3, de 11 de novembro de 1959, expediu instruções para execução da Portaria No 325, sendo que os programas para o exame de admissão poderiam ser baseados na Portaria $\mathrm{N}^{\mathrm{o}}$ 501, ou elaborados pelos próprios estabelecimentos, o que proporcionou certa autonomia aos sistemas de ensino para a elaboração de seus exames (MACHADO, 2002, p. 51). No entanto, essa autonomia nos levantou um questionamento: será que os estabelecimentos não elaboravam exames conforme sua própria programação de ensino, facilitando a aprovação dos alunos? É possível pensar, com essas informações, que se havia estabelecimentos que ofereciam o ensino primário, o curso preparatório e o secundário, e ainda o mesmo estabelecimento preparava seu programa de prova para os exames e preparava os seus próprios exames, então a matemática dos exames poderia estar combinada à matemática a ensinar no primário e à matemática a ensinar no secundário. Essa conjectura nos trouxe mais uma pista para novos estudos sobre as interrelações entre essas "matemáticas".

Quanto ao que ensinava no primário e o que se exigia nas provas, em relação aos conteúdos prescritos, as "matemáticas" dos dois processos estavam próximas. Nos exames, ao longo dos anos, foram cobrados os conteúdos:

Em 1931, com o Decreto no 19.890, a prova de Matemática (Aritmética) deveria apurar o domínio de cálculo elementar. Entretanto, a partir de 1940, além destes, os conteúdos foram ampliados passando a conter os critérios de divisibilidade, números primos, prova real e dos nove, mínimo múltiplo comum e máximo divisor comum, frações, sistema monetário brasileiro e resolução de problemas. Durante o ano de 1943 o conteúdo Sistema Monetário foi suspenso do programa. De 1940 em relação 1951 foi ampliada a resolução de problemas de sistema métrico decimal para sistema legal de unidades de medidas. Em 1952 houve a introdução dos números decimais periódicos ao programa de admissão ao ginásio. Em 1959 o programa de admissão é mantido,

Educação, Psicologia e Interfaces, Volume 3, Número 3, p. 64-78, Setembro/Dezembro, 2019.

ISSN: 2594-5343. DOI: https://doi.org/10.37444/issn-2594-5343.v3i3.206 
Voltando aos exames de admissão ao ginásio (1930-1970): a relação entre a matemática dos exames com a matemática a ensinar e ensinada nas escolas

no entanto, admite restrições quanto ao aprofundamento dos conteúdos (AKSENEN, 2013, p. 99-100).

E conforme relata Santos (2017, p. 99), no "tocante aos programas de ensino primário, foi possível constatar a existência dos conteúdos do saber matemático do primário nos exames de admissão ao ginásio”. A autora percebeu que os conteúdos dispostos nos programas do primário, como por exemplo os conteúdo de moeda brasileira $\left(2^{\circ}\right.$ e $3^{\circ}$ ano), medidas de comprimento, peso e capacidade ( $2^{\circ}$ ano) e frações ordinárias ( $4^{\text {o }}$ ano), do Programa de Ensino de 1934, apareciam nas provas do exame de admissão do Colégio São Paulo no período compreendido entre 1932 a 1942 (SANTOS, 2017). Logo, ao que tudo indica, a matemática a ensinar no primário era contemplada nos exames e os exames prescreviam conteúdos mínimos a serem avaliados. Mas para além disso, a partir do que foi discutido anteriormente, nenhuma relação de dependência entre a matemática a ensinar ou ensinada, e a matemática dos exames, ainda pôde ser confirmada.

\section{CONSIDERAÇÕES FINAIS}

Neste trabalho, questionamos inicialmente se a matemática que era exigida nos exames "moldou" o que deveria ser ensinado na matemática escolar; ou se a matemática dos exames interferiu no que se ensinava no primário. Quanto a essas questões, concluímos que existiu uma relação entre a matemática dos exames com a matemática a ensinar no primário, no sentido de alguns conteúdos prescritos ao primário serem os mesmos exigidos nos exames. Logo, havia uma relação de convergência entre o que se cobrava nos exames e o que deveria ser ensinado, o que estava prescrito em documentos oficiais. Porém, não podemos dizer que o exame impôs condições para que o ensino dos quatro anos do primário se modificasse em função da avaliação que era aplicada, e sim apenas avaliado com rigor a aritmética ensinada no primário.

Também foi identificado, pela metanálise realizada, que alguns professores que lecionavam ao primário foram levados a lecionar em cursos preparatórios para o exame de admissão, o que, supostamente, pode ter interferido na prática de ensino desses professores, atuando no primário e/ou em cursos preparatórios e os levando a reformular práticas já estabelecidas. Aí sim podemos supor um indício de que a matemática dos exames tenha interferido na matemática ensinada, pois alguns primeiros achados nos levam a essa hipótese.

Educação, Psicologia e Interfaces, Volume 3, Número 3, p. 64-78, Setembro/Dezembro, 2019.

ISSN: 2594-5343. DOI: https://doi.org/10.37444/issn-2594-5343.v3i3.206 
Portanto, os indícios revelam que além de um efeito seletivo do alunado da época, os exames de admissão podem ter influenciado de alguma maneira a prática de professores, abrindo, com tudo isso, novos questionamentos a futuras pesquisas sobre um possível efeito dos exames sobre as práticas de ensino ministradas no primário e condicionadas, talvez, pela política avaliativa dos exames.

\section{Notas de rodapé}

${ }^{1}$ Estamos usando o termo "prova" como sinônimo de "avaliação" e de "teste". O termo "exame" será usado para todo o processo que compunha a política avaliativa dos tempos de admissão ao ginásio.

2 "A metanálise é uma revisão sistemática de outras pesquisas, visando realizar uma avaliação crítica das mesmas e/ou produzir novos resultados ou sínteses a partir do confronto desses estudos, transcendendo aqueles anteriormente obtidos" (FIORENTINI; LORENZATO, 2006, p.103 grifo nosso).

${ }^{3}$ Nessa etapa da pesquisa, focamos a relação entre a matemática dos exames com a do primário, pois temos a colaboração de acadêmicas da pedagogia, que nos levaram a focar mais no primário.

${ }^{4}$ Desde 1870 já aconteciam os exames de admissão em nível nacional, mas somente por meio do Decreto No 19.890 de 18 de abril de 1931 é que tais exames tornaram-se obrigatórios nas escolas públicas de todo o Brasil até o ano de 1971 (AKSENEN, 2013).

${ }^{5}$ Eram expressões numéricas que caracterizavam "bem o que significava o domínio das operações fundamentais e o desembaraço no cálculo" [...]. Tipo de exercício que demonstrava o interesse dos avaliadores pelo adestramento para o cálculo e pelas extensas expressões numéricas (MACHADO, 2002, p. 46, 47).

\section{REFERÊNCIAS BIBLIOGRÁFICAS}

AKSENEN, E. Z. Os exames de admissão ao ginásio, seu significado e função na educação paranaense: análise dos conteúdos matemáticos (1930 a 1971).

Dissertação (Mestrado em Educação). Pontifícia Universidade Católica do Paraná. Curitiba, p. 145. 2013.

BERTINI, L. F.; MORAIS, R. S.; VALENTE, W. R. A matemática a ensinar e a matemática para ensinar: novos estudos sobre a formação de professores. São Paulo: Editora Livraria da Física, 2017.

BRASIL. Circular no. 973, de 25 de maio de 1965. Consolidação da Legislação do Ensino Secundário, após a LDBEN - Lei de Diretrizes e Bases da Educação Nacional, 1965.

BRASIL. Governo Provisório da República dos Estados Unidos do Brasil. Decreto $\mathrm{n}^{\mathrm{o}}$ 19.890, de 18 de abril de 1931. Rio de Janeiro, 18 de abril de 1931.

LUSSI BORER, V. Les savoirs: un enjeu crucial de leinstitutionnalisation des formations à leenseignement. In: HOFSTETTER, R.; SCHNEUWLY, B. Savoirs en 
(trans)formation: Au coeur des professions de lee enseignement et de la formation. 1. ed. Bruxelles: De Boeck Supérieur, 2009, p. 41-58.

DALLABRIDA, N. A reforma Francisco Campos e a modernização nacionalizada do ensino secundário. Educação, v. 32, n. 2, 2009.

FIORENTINI, D.; LORENZATO, S. Investigação em educação matemática: percursos teóricos e metodológicos. Campinas, SP: Autores Associados, 2006.

MACHADO, R. C. G. Uma análise dos Exames de Admissão ao Secundário (19301970): subsídios para a História da Educação Matemática no Brasil.

Dissertação (Mestrado em Matemática) - Pontifícia Universidade Católica de São Paulo. São Paulo, p. 130. 2002.

MENEGHETI, P. A trajetória do ensino no brasil: ensino secundário e o exame de admissão. Colóquio "Ensino médio, história e cidadania", v. 2, n. 2, 2012.

SANTOS, R. Saberes matemáticos identificados em provas do exame de admissão ao ginásio do Colégio São Paulo (1931-1969). Dissertação (Mestrado em Ensino de Ciências e Matemática) - Universidade Federal de Sergipe, São Cristóvão, SE, p. 104. 2017.

SÃO PAULO (Estado). Decreto no. 27.017, de 14 de dezembro de 1956. Dispõe sobre a instalação em estabelecimentos Oficiais Estaduais de Ensino Secundário de Cursos Intensivos de Preparatórios a Exames de Admissão e sua Regulamentação, 1956.

VALENTE, W. R. Provas e exames como documentos para estudo da matemática do ensino e da matemática da formação de professores: elementos do saber profissional docente. In: BURIGO, E. Z. et al. Provas, exames e história da educação matemática. 1. ed. Roraima: Editora da Universidade Federal de Roraima, v. 1, 2018.

\section{Credenciais das autoras}

NEVES, Késia Caroline Ramires. Pós-Doutorado pela Universidade Federal de São Paulo, UNIFESP, Brasil. Doutora em Educação para a Ciência e a Matemática (Universidade Estadual de Maringá - UEM - 2016). Mestra em Educação para a Ciência e a Matemática (UEM - 2009). Professora Adjunta da Universidade Federal de Mato Grosso do Sul. Líder do Grupo de Estudos e Pesquisa em Educação Matemática Escolar (GEPEME). Integrante do Grupo de Pesquisa de História da Educação Matemática (GHEMAT-SP). E-mail: kesiaramires@ hotmail.com

MARTTI, Fernanda Cristina Martins. Graduanda em Pedagogia pela Universidade Federal de Mato Grosso do Sul. E-mail:marttins671@gmail.com

ALFONSO, Dina Elizabete. Graduanda em Pedagogia pela Universidade Federal de Mato Grosso do Sul. E-mail: dinaelizabete5 @ gmail.com. 
Endereço para correspondência: Késia Caroline Ramires Neves. E-mail: kesiaramires@hotmail.com

Como citar este artigo (Formato ABNT): NEVES, Késia Caroline Ramires; MARTTI, Fernanda Cristina Martins; ALFONSO, Dina Elizabete. Voltando aos exames de admissão ao ginásio (1930-1970): a relação entre a matemática dos exames com a matemática a ensinar e ensinada nas escolas. Educação, Psicologia e Interfaces, v. 3, n.3, p.64-78, 2019. DOI: https://doi.org/10.37444/issn-2594-5343.v3i3.206

Recebido: 07/11/2019.

Aceito: 06/12/2019. 